\title{
Toward a limited realism for psychiatric nosology based on the coherence theory of truth
}

\author{
K. S. Kendler* \\ Departments of Psychiatry, and Human and Molecular Genetics, Virginia Institute of Psychiatric and Behavioral Genetics, Medical College of \\ Virginia/Virginia Commonwealth University, Richmond, VA, USA
}

\begin{abstract}
A fundamental debate in the philosophy of science is whether our central concepts are true or only useful instruments to help predict and manipulate the world. The first position is termed 'realism' and the second 'instrumentalism'. Strong support for the instrumentalist position comes from the 'pessimistic induction' (PI) argument. Given that many key scientific concepts once considered true (e.g. humors, ether, epicycles, phlogiston) are now considered false, how, the argument goes, can we assert that our current concepts are true? The PI argument applies strongly to psychiatric diagnoses. Given our long history of abandoned diagnoses, arguments that we have finally 'gotten it right' and developed definitive psychiatric categories that correspond to observer-independent reality are difficult to defend. For our current diagnostic categories, we should settle for a less ambitious vision of truth. For this, the coherence theory, which postulates that something is true when it fits well with the other things we confidently know about the world, can serve us well. Using the coherence theory, a diagnosis is real to the extent that it is well integrated into our accumulating scientific data base. Furthermore, the coherence theory establishes a framework for us to evaluate our diagnostic categories and can provide a set of criteria, closely related to our concept of validators, for deciding when they are getting better. Finally, we need be much less skeptical about the truth status of the aggregate concept of psychiatric illness than we are regarding the specific categories in our current nosology.
\end{abstract}

Received 19 May 2014; Revised 29 July 2014; Accepted 5 August 2014; First published online 2 September 2014

Key words: Coherence theory of truth, pessimistic induction, philosophy, psychiatric nosology, validity.

All past beliefs about nature have sooner or later turned out to be false (Kuhn, 1992, p. 14).

A central debate in the philosophy of science is whether central scientific concepts such as 'mass', 'gene', 'electron', 'oxygen' and 'black hole' accurately reflect how the world really is or are better understood as useful categories that help us to organize, predict and manipulate the world. The first position is called scientific realism and the second scientific instrumentalism (Chakravartty, 2014).

In common sense terms, scientific realism postulates that science should seek and is capable of discovering the truth about the world as it exists independent of human observation. Frequently, these truth claims incorporate theoretical entities that scientists postulate but cannot, at that time, observe directly. The electron at the time of Thompson (Davis \& Falconer, 1997) and the gene at the times of Mendel and Morgan (Griffiths

* Address for correspondence: K. S. Kendler, M.D., Departments of Psychiatry, and Human and Molecular Genetics, Virginia Institute of Psychiatric and Behavioral Genetics, Medical College of Virginia/ Virginia Commonwealth University, Box 980126, Richmond, VA 23298-01261471, USA.

(Email: kendler@vcu.edu)
\& Stotz, 2013) would be good examples. Such entities are not seen as merely convenient constructs but rather, they are understood to be real.

Instrumentalists are less ambitious and more wary of philosophical claims. Why worry about the theoretical questions of 'reality', when all we really want to do is represent what is out there (as our 'instruments') so that we predict and intervene successfully in the world? Scientific instrumentalists would argue that scientists should concentrate on the practical problems at hand and leave the elaboration about mind-independent reality to those who enjoy metaphysical speculation.

This debate has also occurred about psychiatric disorders. Are our current psychiatric categories (schizophrenia, major depression, antisocial personality disorder) best understood as real entities that exist in some classification-independent way or as pragmatic constructions created for particular purposes; to predict treatment response, course of illness, brain imaging findings or genetic results?

In discussions for and against scientific realism, strong support for the instrumentalist position has come from what has been called the 'pessimistic induction' (PI) argument (Psillos, 1996). Considering the history of scientific theories in any particular discipline (e.g. astronomy, genetics, physics, psychology), over 
time, older theories have continuously been replaced by newer ones. This in fact often defines scientific progress. Thus, sitting in the present, we can look back at earlier theories, since replaced, and see entities and processes referred to by these theories that are no longer considered to be real. For example, planets do not travel in epicycles as they circle the earth, ether does not exist and inheritance is not (typically) Lamarckian in nature.

If the PI argument is true in the present, it is highly likely that it will also be true in the future. Therefore, in looking back from the future, the scientific constructs that we now regard as real will probably also be replaced and viewed as largely false. An argument against this PI could be mounted. It would go something like this: 'All those prior scientists were mistaken about the value of their theories. But we finally have things right. The entities referred to by our current best theories are real. The truth is now in our hands'. That argument, however, smacks of hubris. It argues that no further self-correction is possible. Such finality does not fit well with the scientific attitude. [In the interest of balance, I should also mention the 'no miracles' argument in favor of scientific realism first articulated by Putnam (1975). In essence, Putnam argued that the practical success of modern science would be a miracle unless we admit that much of what it postulates is in fact true.]

A key component of the PI argument is that, as noted, scientific theories often postulate the existence of unobservable theoretical entities. Over time, as scientific theories are replaced, many of these unobservables are judged to be false, to have never existed. In one of the most important articulations of the PI argument, Laudan (1981) gave a list of such theoretical entities postulated by failed theories that we now know do not 'refer to' anything in the real world. That is, in philosophy speak, they are 'neither true nor even approximately true'. Here is Lauden's list, enumerated for clarity:

(i) the crystalline spheres of ancient and medieval astronomy; (ii) the humoral theory of medicine; (iii) the effluvial theory of static electricity; (iv) 'catastrophist' geology, with its commitment to a universal (Noachian) deluge; (v) the phlogiston theory of chemistry; (vi) the caloric theory of heat; (vii) the vibratory theory of heat; (viii) the vital force theories of physiology; (ix) the electromagnetic ether; (x) the optical ether; (xi) the theory of circular inertia; and (xii) theories of spontaneous generation.

He ends this list by noting that it 'could be extended ad nauseam' (Laudan, 1981, p. 33).

How forcefully does the PI argument apply to our current psychiatric disorders? With what kind of strength can we argue that our constructs for disorder can be considered to correspond to reality and will be regarded as such for decades if not centuries to come? Or, are our current diagnostic categories more like phlogiston: useful in its time (Chang, 2004, 2012) but ultimately proven false by advancing science?

Anyone with a smattering of knowledge of psychiatric history would have little problem in creating a list of 12 abandoned psychiatric disorders that at one time were widely used and considered true but are no longer considered useful and would perhaps be judged to be 'false'. One such list would be: (i) paraphrenia; (ii) neurasthenia; (iii) phrenzy; (iv) periodic hallucinatory insanity; (v) drapetomania (Cartwright, 2004); (vi) monomania (Esquirol, 1845); (vii) lypemania (Esquirol, 1845); (viii) demonomania (Esquirol, 1845); (ix) anxiety-happiness psychosis (Leonhard, 1979); (x) cataphasia, (Leonhard, 1979); (xi) confabulatory euphoria (Leonhard, 1979); and (xii) hysteria.

The PI argument applied to current psychiatric disorders argues strongly against what might be called a 'hard' realism model for psychiatric disorders. The paradigmatic scientific example of categories that meet criteria for hard realism is the elements in the periodic table. This is because we have high confidence that individuals studying chemistry a hundred or a thousand years from now will be examining something like our current periodic table. It describes something deeply true about the way our world works. We cannot plausibly make that claim for the psychiatric disorders that currently populate our diagnostic manuals.

One solution would be to give up on the hard realism project for psychiatric disorders and settle for a purely instrumentalist position. But I will try here to be more ambitious in two ways. The first is an argument for 'type realism' for our aggregate disorders. The second advocates a 'graduated realism' based on a different and humbler idea of what it means to be 'real'.

By type realism, I mean that we can mount a strong argument for a realist position for psychiatric disorders in aggregate. The fact that humans are vulnerable to substantial dysfunctions of their mind/brain systems, which lack localizing neurologic signs and cause much suffering and disability, is a robust fact about our world. It will be here in a hundred or a thousand years, or would arise if we played the tape of time over and over again starting with the rise of our species. However, we can be much more confident about the reality of the broad 'type' (aka overarching category) of psychiatric illness than we can be by the specific forms (aka particular disorders) that we now use. Hoche, in an essay in 1912, used a useful, albeit cynical, metaphor for the exercise of psychiatric nosology (Hoche, 1991). This involved taking a liquid 
and pouring it from one set of bottles into another, each time thinking we were doing a better job of dividing them up. To adopt Hoche's metaphor, I argue we can be much more confident about the existence of the liquid than the particular bottles in which it is now residing. I do not want to argue that this approach to type realism solves the questions about the boundaries of psychiatric illness (Bolton, 2008). I only assert that we can agree that many of our disorders are sufficiently clear in their impact on human functioning and suffering to, in aggregate, have a strong claim to type realism.

Before proceeding further, I need to take a metaphysical detour and review briefly theories of truth. The standard approach to truth is the 'correspondence theory', which assumes that a statement (or theory) is true if it corresponds to a stable, mind-independent reality. This is a plausible way to think about the elements of the periodic table, but it is poor way to think about psychiatric disorders.

For psychiatric disorders, we need a less ambitious version of reality. A humbler approach can be found in the coherence theory of truth. This theory postulates that something is true when it fits well with the other things we know confidently about the world. Think about a table with a puzzle on it, all assembled but missing one piece. Think about the satisfaction you feel when you find that piece and fit it neatly into the missing space with a pleasing 'snap'. The puzzle is now complete. Surely, you have found the spot where it belongs. In this metaphor, the other pieces in the puzzle are facts about the world you have reason to think are true. The missing piece is a new piece of information that might be true. But when you put this piece into its proper context, it both fits perfectly into place and highlights new aspects of the other pieces (in this case the completed puzzle) that you previously could not see. It seems 'true'.

The coherence theory of truth captures a central feature of scientific intuition, again best illustrated by a story. You have made a strong prediction for a novel and exciting theory. You develop one experiment to verify it and it works. The results are as predicted. But you are not satisfied. You try a second completely different kind of experimental approach and then a third. They all confirm your predictions. You now have a strong conviction of the truth of your theory because these many results cohere in suggesting that its predictions can be confirmed.

The field of psychiatry has been making slow but real progress in linking the clinical symptoms and signs we use to create our diagnostic categories and the underlying etiologies at biological, psychological and environmental levels. Let's try to 'stretch' the puzzle model to psychiatric science. Think of a large puzzle space sparsely populated with pieces. Strings connect some of the pieces indicating prior empirical relationships. Some of the strings are thick and strong (think schizophrenia and genetics), others much thinner and more tentative (think dietary fish oil and major depression). What do we mean in this metaphorical space when we want to say that a diagnosis is 'real'?

Before answering that, let's consider the simpler question: 'What do we mean in this metaphorical space when we want to say that one diagnostic concept is more real than another?' Here, the answer is simple. To be more real means to be connected to more already existing pieces and/or to be connected by stronger strings. So what then do we mean to say a diagnosis is real? We might say it is 'pretty well' connected with the other pieces, that it is 'pretty well' integrated into our accumulating scientific data base. In other words, a diagnosis is real to the degree that it 'coheres' well with what we already know empirically and feel confident about.

This definition of reality lacks the metaphysical clarity and beauty of the correspondence theory. However, it also does not rely on inferences about what exists independently of our classifications or suggest a finality to our current understanding, a finality of which we should be wary. It also lacks the definitiveness of snapping that last piece into the puzzle. But we have (at least) a few more iterations of DSM before we can expect that to occur.

The coherence theory of truth has one more important benefit to offer us. The other pieces and the connecting strings of our metaphor for the coherence theory are what we have called validators since the days of Robins \& Guze (1970; Kendler 1980, 2013). The best diagnoses we have are the ones that are heavily intertwined with other things we know about; that is, are 'well validated'. For individuals assigned to that class, we follow the strings and see all the other things that we learn about them: genetic risk factors, premorbid susceptibilities, imaging findings, neurochemistry, course, prognosis, treatment, etc. As a disorder becomes more valid, it becomes more connected with our knowledge base and, from a coherence perspective, more 'true'.

As noted above, the coherence theory provides a simple framework for what it might mean to make our constructs refer to something more real. We should require, for each iteration of our diagnostic manual, that changes be made in our diagnostic categories only when they result in the diagnosis becoming 'more real', which by the coherence theory means more interwoven with the fabric of our scientific findings (Kendler, 2012; but see also Schaffner, 2012).

Finally, it is highly likely that psychiatric disorders will never have a correspondence to reality with the 
clarity of oxygen, nitrogen and carbon. They are simply too messy and the human mind-brain system too complex and flexible. Furthermore, validation is broadly the equivalent of corroboration, and as such it is always provisional in science. Rather, the best we could strive for is to have them well entrenched within our multifactorial coherence framework. Furthermore, we may not be able to categorize psychiatric disorders so that they optimally link to all kinds of validators and may have to decide which kind of coherence we value most (Kendler, 1990). Our goal might be to have our diagnoses so well connected by many (if not all possible) strong strings of science that they 'nearly' snap into place like that last piece of the puzzle.

\section{Conclusions}

A hard realism model for our psychiatric disorders based on the correspondence theory of truth is too high a standard for the field of psychiatry to meet. The pessimistic induction argument is too convincing. Cogent arguments that we have finally 'gotten it right' and developed definitive psychiatric categories that correspond to reality cannot be defended. However, that does not mean that we should give up on our goal of grounding our psychiatric disorders in the matrix of the empirical world, nor should we retreat from our claim that in aggregate the psychiatric disorders are deeply real. But for our current diagnostic categories, we should settle for a humbler metaphysics, a less ambitious vision of truth. For this, the coherence theory can serve us well. It provides a 'scalable' concept of truth appropriate for our status as a young science dealing with the most complex entities imaginable. Furthermore, the coherence theory establishes a framework for us to evaluate our diagnostic categories and can provide a set of criteria for deciding when they are getting better.

\section{Acknowledgments}

J. Campbell and P. Zachar provided helpful comments on earlier versions of this essay.

\section{Declaration of Interest}

None.

\section{References}

Bolton D (2008). What is Mental Disorder? An Essay in Philosophy, Science, and Values. Oxford University Press: New York, NY.
Cartwright SA (2004). Report on diseases and physical peculiarities of the Negro race (original work published 1851). In Health, Disease, and Illness, 1st edn (ed. A. L. Caplan, J. J. McCartney and D. A. Sisti), pp. 28-39. Georgetown University Press: Washington, DC.

Chakravartty A (2014). Scientific Realism. In The Stanford Enyclopedia of Philosophy, Spring 2014 Edition (ed. E. N. Zalta) (http://plato.stanford.edu/archives/spr2014/ entries/scientific-realism/).

Chang H (2004). Inventing Temperature: Measurement and Scientific Progress. Oxford University Press: New York, NY.

Chang H (2012). Is Water $\mathrm{H}_{2} \mathrm{O}$ ? Evidence, Realism and Pluralism. Springer: Cambridge, UK.

Davis EA, Falconer I (1997). J.J. Thompson and the Discovery of the Electron. Taylor \& Francis Ltd: London.

Esquirol JED (1845). Mental Maladies. A Treatise on Insanity. Translated from the French, with additions, by E. K. Hunt. Lea and Blanchard: Philadelphia, PA.

Griffiths P, Stotz K (2013). Genetics and Philosophy: An Introduction. Cambridge University Press: Cambridge, UK.

Hoche A (1991). The significance of symptom complexes in psychiatry (trans. by R. G. Dening and T. R. Dening). History of Psychiatry 2, 329-343.

Kendler KS (1980). The nosologic validity of paranoia (simple delusional disorder). A review. Archives of General Psychiatry 37, 699-706.

Kendler KS (1990). Toward a scientific psychiatric nosology. Strengths and limitations. Archives of General Psychiatry 47, 969-973.

Kendler KS (2012). Epistemic iteration as a historical model for psychiatric nosology: promises and limitations. In Philosophical Issues in Psychiatry II: Nosology (ed. K.

S. Kendler and J. Parnas), pp. 303-322. Oxford University Press: Oxford, UK.

Kendler KS (2013). A history of the DSM-5 Scientific Review Committee. Psychological Medicine 43, 1793-1800.

Kuhn TS (1992). The Trouble with the Historical Philosophy of Science: Robert and Maurine Rothschild Distinguished Lecture; 19 November 1991. Department of the History of Science, Harvard University: Cambridge, MA.

Laudan L (1981). A confutation of convergent realism. Philosophy of Science 48, 19-49.

Leonhard K (1979). The Classification of Endogenous Psychoses: Translated from the German by Russell Berman. Irvington Publishers, Inc.: New York, NY.

Psillos S (1996). Scientific realism and the 'pessimistic induction'. Philosophy of Science 63, S306-S314.

Putnam H (1975). Mathematics, Matter and Method. Cambridge University Press: New York, NY.

Robins E, Guze SB (1970). Establishment of diagnostic validity in psychiatric illness: its application to schizophrenia. American Journal of Psychiatry 126, 983-987.

Schaffner KF (2012). Coherentist approaches to scientific progress in psychiatry: comments on Kendler. In Philosophical Issues in Psychiatry II: Nosology (ed. K. S. Kendler and J. Parnas), pp. 323-330. Oxford University Press: Oxford, UK. 